\title{
A multilevel investigation of inequalities in clinical and psychosocial outcomes for women after breast cancer
}

\author{
Philippa H Youl ${ }^{1,2^{* \dagger}}$, Peter D Baade ${ }^{1,2,3 \dagger}$, Joanne F Aitken ${ }^{1,2+}$, Suzanne K Chambers ${ }^{2,1,4 \dagger}$, Gavin Turrell ${ }^{3 \dagger}$, \\ Christopher Pyke ${ }^{5+}$ and Jeffrey Dunn ${ }^{1+}$
}

\begin{abstract}
Background: In Australia, breast cancer is the most common cancer affecting Australian women. Inequalities in clinical and psychosocial outcomes have existed for some time, affecting particularly women from rural areas and from areas of disadvantage. We have a limited understanding of how individual and area-level factors are related to each other, and their associations with survival and other clinical and psychosocial outcomes.
\end{abstract}

Methods/Design: This study will examine associations between breast cancer recurrence, survival and psychosocial outcomes (e.g. distress, unmet supportive care needs, quality of life). The study will use an innovative multilevel approach using area-level factors simultaneously with detailed individual-level factors to assess the relative importance of remoteness, socioeconomic and demographic factors, diagnostic and treatment pathways and processes, and supportive care utilization to clinical and psychosocial outcomes. The study will use telephone and self-administered questionnaires to collect individual-level data from approximately 3, 300 women ascertained from the Queensland Cancer Registry diagnosed with invasive breast cancer residing in 478 Statistical Local Areas Queensland in 2011 and 2012. Area-level data will be sourced from the Australian Bureau of Statistics census data. Geo-coding and spatial technology will be used to calculate road travel distances from patients' residence to diagnostic and treatment centres. Data analysis will include a combination of standard empirical procedures and multilevel modelling.

Discussion: The study will address the critical question of: what are the individual- or area-level factors associated with inequalities in outcomes from breast cancer? The findings will provide health care providers and policy makers with targeted information to improve the management of women with breast cancer, and inform the development of strategies to improve psychosocial care for women with breast cancer.

\section{Background}

Breast cancer is the most common cancer in women worldwide. It is estimated that 1.38 million women will be diagnosed with breast cancer in 2008 [1]. In Australia in $2007,12,567$ women were diagnosed with breast cancer accounting for $27 \%$ of cancer diagnoses. Breast cancer is the second leading cause of cancer mortality ( $15 \%$ of all cancer deaths) overall, [2] and among women, it is the leading cause of premature mortality due to cancer [3].

\footnotetext{
* Correspondence: pipyoul@cancerqld.org.au

+ Contributed equally

'Viertel Centre for Research in Cancer Control, Cancer Council Queensland,

PO Box 201, Spring Hill, QLD, 4004, Australia

Full list of author information is available at the end of the article
}

Women diagnosed with breast cancer carry a significant psychological burden. Prevalence studies suggest that $33 \%$ of women with breast cancer will experience clinically significant psychological distress (e.g. anxiety and/or depression) that for many will persist over time, [4] and approximately one-third report moderate to high unmet supportive care needs after their diagnosis [5].

Inequalities in survival, recurrence, treatment and psychosocial outcomes

There is a consistent rural gradient in breast cancer incidence, being higher in major cities, and lower in more rural areas [6-8]. In contrast survival tends to be lower for women living in more rural areas. In Queensland Australia,
C Biomed Central

(c) 2011 Youl et al; licensee BioMed Central Ltd. This is an Open Access article distributed under the terms of the Creative Commons Attribution License (http://creativecommons.org/licenses/by/2.0), which permits unrestricted use, distribution, and reproduction in any medium, provided the original work is properly cited. 
relative survival from breast cancer was 14\% lower among women from inner regional areas, 24\% lower in outer regional areas and $41 \%$ lower in remote areas compared to the major city area with similar patterns observed in other Australian states $[9,10]$. Patterns of treatment also vary geographically with women living in rural and remote areas up to $70 \%$ more likely to receive a mastectomy than breast conserving surgery, independent of disease stage [11]. Possible factors contributing to this differential include the need for women in rural areas to travel greater distances to radiotherapy services and lack of local access to tertiary hospitals $[11,12]$. Additionally, there is some evidence to suggest that rural women may perceive, or actually have, less control over treatment decisions, and this may be due to limited access to information about options for breast cancer treatment [13]. Emerging evidence suggests that rural cancer patients experience greater psychological morbidity than do their urban counterparts [14] and rural women report more unmet needs for help in dealing with fears about cancer recurrence [5].

\section{Possible reasons for observed inequalities in outcomes Stage}

Differences in stage are a possible reason for the observed differences in breast cancer survival. Cancer stage is the most strongly predictive of all clinical prognostic factors: 5 -year relative survival rates vary from about $98 \%$ for women with tumours $\leq 10 \mathrm{~mm}$ to $73 \%$ for women with tumours $30 \mathrm{~mm}+$ and $49 \%$ for those women with tumours of unknown size [10]. However a recent ecological study in Queensland, Australia found significant differences in 5 -year survival by rurality that remained after adjusting for spread of disease, [10] suggesting these differences in survival are not explained by geographical variation in the proportions of women diagnosed with early versus late stage breast cancer.

\section{Age}

There is biological evidence to suggest that breast cancer among younger women is a distinct disease [15]. Tumours tend to be larger, less well differentiated, more likely to be lymph-node positive and more likely to metastasise compared to tumours found in older women. As a result, prognosis is significantly worse among younger breast cancer patients, and they are more likely to experience recurrence [15-17]. Compared to older women, women less than 50 years of age are more likely to experience high levels of psychological distress after breast cancer and greater ongoing psychosocial support needs [18]. Younger women also experience more problems with sexual well-being after breast cancer, [19] including concerns about premature menopause; fertility and sexual functioning; [20] greater decrements in social well-being; greater financial difficulties; [21] and they consistently report that existing supportive care services do not match their needs [22].

\section{Risk factors}

Apart from age and family history, risk factors for breast cancer include reproductive or hormonal factors, [23] as well as health-related factors such as obesity, smoking, alcohol intake and reduced levels of physical activity [24-26]. Those living in rural areas and areas of disadvantage are more likely to have poorer health-related behaviours [27]. Further, a high body mass index and current smoking have been found to be associated with reduced survival [28].

\section{Access to screening and health services}

Screening for breast cancer in asymptomatic women is estimated to reduce mortality by $20 \%$ to $35 \%$ [29,30]. In Australia, free biennial population-based screening is available for women in the target age group of 50 to 69 years, although women aged 40-49 years and over 70 years are also able to take part. Approximately 55\% of Australian women in the target age group participated in the breast screen program in 2007-2008 [31]. While higher participation rates have been observed in regional and remote areas compared to major cities, low participation rates have been observed in the most socially disadvantaged areas and among Indigenous women [32].

Location of and access to, health services have been recognised as important contributors to morbidity and mortality in Australia and elsewhere. While the increasing centralisation of health care services [33] is supported by evidence that the best outcomes are obtained when patients are treated by practitioners and institutions with high caseloads, [34] this centralisation has implications for rural cancer patients' access to diagnostic and treatment services. Typically rural patients need to travel longer distances to access those services, and this may be a disincentive to undertake or complete treatment regimens. This is particularly relevant when the treatment involves a prolonged absence from home resulting in disruptions to family life and financial hardship [35].

\section{Indigenous status}

While the incidence of breast cancer in Indigenous Australian women is lower than that of non-Indigenous women, it is still the most common cancer in this group $[6,36]$. Once diagnosed with breast cancer, Indigenous women have significantly poorer survival than their nonIndigenous counterparts [10]. One factor contributing to this disparity is that Indigenous Australians are significantly more likely to live in rural and remote areas than are non-Indigenous Australians [37].

\section{Socioeconomic status}

In Australia the incidence of breast cancer is about 15\% higher for women living in areas of high SES compared to those living in the most disadvantaged areas [6]. Similar patterns have been observed in the USA and Europe with incidence rates about $10-20 \%$ higher for women living in the least deprived areas [38-40]. However, women 
in disadvantaged areas have poorer survival and higher rates of recurrence. While some of the survival differential is explained by stage of disease, significant differences in survival remain after adjustment for tumour size, stage, age at diagnosis and treatment [41,42]. In a recent study examining both area- and individual-level SES, after adjustment, there remained a persistent association for higher mortality for women who lived in communities where a high proportion of residents had limited educational attainment [43].

SES also influences choice of treatment with women from lower SES groups significantly less likely to undergo breast conserving surgery independent of disease stage and less likely to undergo or to complete adjuvant therapy despite this being the recommended treatment $[44,45]$. Lower SES has also been shown consistently to predict poorer psychological outcomes after cancer [46].

\section{Area-level versus individual- level factors}

Most studies examining area variation in cancer outcomes have used an aggregate ecologic design $[47,48]$. This has well-documented conceptual and statistical difficulties in interpretation [49]. Survival studies using aggregated ecologic data are unable to quantify whether the variations in survival are likely due to the clustering of individuals or the environmental characteristics of the areas in which the individuals live. Ecologic studies leave open the possibility that variation between clinical and psychosocial outcomes is explained by varying population compositions, and unless these are taken into account, area- and individuallevel sources of variation are confounded.

By obtaining detailed information about individual breast cancer patients through clinical records, telephone interviews and self-administered questionnaires, supplemented by area-specific information, this study will incorporate a multilevel approach to investigating inequalities in outcomes, and thus overcome many of the methodological and interpretive problems of ecologic studies.

\section{Study Aims}

1. To systematically describe modes of presentation, time to diagnosis, diagnostic and treatment pathways, utilisation of psychosocial care services, unmet supportive care needs, perceptions of control over treatment decisions, rates of recurrence and survival for women newly diagnosed with breast cancer.

2. To examine differences in these factors according to individual characteristics (including age $(<$ 50 years, 50-69 years and 70+ years), spread of disease, co-morbidity and individual-level socioeconomic status) and area-level characteristics including geographical remoteness, area socioeconomic disadvantage.
3. To model the independent contribution that arealevel and individual-level factors make to the variation in recurrence and survival from breast cancer.

\section{Methods/Design}

\section{Funding and support}

This project was awarded funding by Cancer Australia (ID: 1006339). Cancer Council Queensland provided additional funding for the maintenance of the GIS software and for the long-term follow-up of breast cancer cases.

\section{Ethical clearance}

Approval for the study was obtained from the Human Research Ethics Committee of Griffith University, Australia (PSY/C4/09/HREC). Additional clearance to access confidential health information was obtained from the Research Ethics and Governance Unit, Queensland Health.

\section{Study Design}

This study involves the collection and modelling of individual- and area-level data. Individual-level data will be obtained through a longitudinal study of women newly diagnosed with breast cancer. Quantitative and qualitative data will be collected by Computer Assisted Telephone Interview (CATI) and self-administered questionnaires (SAQ) at two time points: 4 to 6 months post diagnosis (Time 1) and 18 months post-diagnosis (Time 2). Clinical and treatment information will be obtained from medical records at 12 months post diagnosis. Information on mammographic screening, surgical and other therapeutic procedures will be obtained from BreastScreen Australia, Medicare Australia and through the Queensland Hospital Admitted Patient Data Collection (QHAPD). Information on recurrence and survival will be obtained using Queensland and interstate Cancer Registries and the National Death Index. Area-level data will be obtained from the Australian Bureau of Statistics.

\section{Setting}

The study will be conducted in Queensland Australia. Queensland is the third largest Australian state by population with an estimated resident population of 4.5 million (2010). Queensland is the most decentralised state in Australia with approximately $40 \%$ of its population living outside of its capital city and surrounding area [50].

\section{Study participants}

Eligible participants will be all women aged 20 to 79 years resident in Queensland, Australia with a histologically confirmed diagnosis of invasive breast cancer (ICD0-3 C50) between January 12011 and December 31 2012 and notified to the Queensland Cancer Registry 
(QCR). The QCR is a population-based register with virtually universal coverage of individuals diagnosed with cancer in Queensland. Notification of cancer is a statutory requirement for all pathology services, private and public hospitals and nursing homes in Queensland.

Based on Queensland incidence rates, [9,51] and allowing for increasing trends in counts, [9] it is anticipated that approximately 5, 185 women will be eligible. Patients' name and the names of their treating doctors will be obtained from the QCR using a rapid ascertainment procedure that will minimise the time from diagnosis to ascertainment to approximately four months. Following doctor's consent, all patients will be forwarded a study information sheet, consent form and reply-paid envelope along with a letter from their doctor informing them of the study. Participants will also be asked to provide consent for researchers to access their records within the QCR and to allow matching of their name to other data sources. Non-responding patients will be followed-up by repeat mailing and telephone.

\section{Data collection \\ Individual-level data}

Information obtained from telephone and selfadministered questionnaires Participants will receive a structured telephone interview and a self-administered questionnaire (SAQ) at 4 to 6 months (Time 1 ) and at 18 months (Time 2) post diagnosis. Information collected will include socio-demographics, self-reported diagnostic and treatment information, medical information, attitudes to help seeking, utilisation and availability of psychosocial and supportive care, psychological distress and quality of life.

Socio-demographics will include education, marital status, occupation, private health insurance, gross household income (pre and post diagnosis), number of dependent children at home and Indigenous status.

Medical history will include family history of breast cancer, birth weight, age at menarche, menopausal status, parity, history of breastfeeding, use of oral contraceptives and hormone replacement therapy (HRT), complementary therapies, current weight, pre-diagnosis weight, preexisting medical conditions, smoking, and alcohol consumption and levels of physical activity.

Pathways to diagnosis will include history of mammography (through public and private facilities), symptoms and date of first recognition of abnormality (for symptom detected), date of mammography (for screen detected), date and outcomes of first appointment with doctor, date and outcomes of any subsequent appointments up to the date of diagnosis, methods of transport and time taken to attend diagnostic tests, satisfaction with the process of diagnosis (including perceived delays, reasons for delays).
Treatment pathways will include treatment types and corresponding dates, location of treatment facility, time taken and method of transport to attend treatments, satisfaction with medical care and health system, reasons for treatment choices, perceived degree of control over choices and barriers from the patient's perspective.

Psychosocial outcomes will be assessed using a number of previously validated instruments including the Attitudes to Seeking Help after Cancer (ASHCa) a 20 item scale that assesses positive and negative attitudes to seeking emotional or psychological support after cancer and behavioural intention to seek support [31,52]. The Supportive Care Needs Survey Short Form 34 (SCNS-SF34) a 34-item survey assessing cancer patients' need for help over the last month across 5 domains: psychological, health systems and information, patient care and support, physical and daily living, and sexuality needs. It has well demonstrated reliability and validity in cancer populations [53]. Perceptions of control over treatment choices will be assessed using questions developed by Street and Voigt [54] and Jansen et al. [55]The Brief Symptom Inventory - 18 (BSI18) will be used to assess psychological distress through three subscales of anxiety, depression, and somatisation. This scale has been well validated in oncology settings and has also been validated with non-clinical populations in the community [56]. Finally, Quality of Life will be assessed using the FACT-B, which has good reliability and validity and has been used in rural patients and among breast cancer survivors in Australia $[57,58]$. The FACT-B assesses physical, social, emotional and functional wellbeing.

Queensland Cancer Registry Data Information obtained from the QCR will include date of birth, address at diagnosis, treating physician's name and contact details, date of diagnosis, tumour site, morphology, histological grade, stage, degree of lymph node involvement, oestrogen and progesterone status. Indigenous status will also be collected from QCR records and will be cross-checked against information provided by the participant during the telephone-based interview.

Medical record data At 12 months after diagnosis, information on diagnosis and treatment including diagnostic tests, presenting symptoms, type and date of surgical procedures, post-operative complications and other therapy (radiation, cytotoxic or hormonal therapy), including start and completion dates will be extracted from clinician and hospital records. Information on indicators of illness status and disease progression including stage, tumour site, maximum tumour diameter, lymph node status, presence of distant metastases and other prognostic indicators will also be obtained. Mammographic history (including dates, location and results) will be obtained from the relevant public or private breast screening services. 
Medicare information Australia's universal health care system (Medicare) provides access to free treatment at a public hospital and free or subsidised treatment by medical practitioners and specialists. Following additional consent from study participants, data relating to specialist attendances, surgical and therapeutic procedures, and pharmaceutical usage will be extracted from the Medicare database from $1^{\text {st }}$ January 2011 for the next five years.

Long-term follow-up of participants Using the QCR, other Australian state and territory cancer registries, and Australia's National Death Index, participants will be followed for a total of five years from their date of diagnosis for breast cancer recurrence, diagnosis of other primary cancers, and death (classified as breast cancer, other cancer or non-cancer death).

\section{Area-level information}

Statistical local areas (SLA) will be the primary focus for area-level analysis. SLAs comprise a group of census collection districts (CDs), the smallest geographical area used by the Australian Bureau of Statistics. In 2006 there were 478 SLAs in Queensland with a median population of 5, 810 individuals. SLAs are often based on the incorporated bodies of local governments who are responsible for service provision and infrastructure at the local and regional level.

Remoteness Remoteness of residence when diagnosed with breast cancer will be categorised using the ARIA+ classification, which is a measure of accessibility and remoteness based on geographical location [59]. This classification includes Major City, Inner Regional, Outer Regional, Remote and Very Remote.

Access to cancer treatment centres and medical care As the ARIA+ classification does not account for access to specialised treatment facilities, specific categories based on distance to and from each facility will be developed. Distance to treatment facilities will be calculated from the participant's place of residence. Address details for breast cancer patients, treatment facilities and diagnostic services will be geocoded using the Manifold ${ }^{\circledR}$ GIS System, a commercial package designed to clean and convert address information into latitude and longitude coordinates. Road travel distances and times between these locations will be calculated using Manifold ${ }^{\circledR}$ GIS system, combined with street network analysis and custom GIS applications.

Measures of socioeconomic status Area-level socioeconomic disadvantage will be measured using the Index of Relative Socioeconomic Disadvantage (IRSD) calculated by the Australian Bureau of Statistics (ABS) [60]. The IRSD provides a general measure of disadvantage, and considers factors such as low income, low educational attainment, high unemployment, and jobs in unskilled occupations. Area-level information about education levels, household income, types of occupation, median mortgage and rental payments and other socioeconomic indicators (corresponding to the relevant information collected at the individual level) by age group and sex for each SLA will be obtained from the census data files released by the ABS for 2006 and 2011.

Life expectancy Average life expectancy will be calculated from the unit record mortality file for Queensland from the ABS that contains year-specific details of allcause mortality by SLA.

\section{Primary outcome measures}

Diagnostic pathways will be assessed through the collection of information describing events and the time period from participants' first noticing symptoms or first abnormality on routine screening exam to first presentation to the medical practitioner. The diagnostic interval will be calculated as the time between initial presentation and the definitive diagnosis.

Treatment pathways will include a description of events and the time taken from definitive diagnosis to the commencement of primary treatment and then the time taken from primary treatment to subsequent treatment(s).

Time to recurrence will be calculated from the date of initial diagnosis to the date of first recurrence. Survival will be calculated from the date of initial diagnosis to the end of the follow-up period (five years) or death.

\section{Sample size and power calculations}

Based on the number of women diagnosed with breast cancer in Queensland from 2005-2007, [51] and recent trends in incidence counts, approximately 5, 185 women aged 20 to 79 years at diagnosis will be eligible for the study. Survival with breast cancer in Queensland is 95.5\% one year after diagnosis and $91.3 \%$ at two years. Assuming that, doctor's permission is obtained to contact $85 \%$ of patients, and $75 \%$ of these patients agree to participate with an additional $5 \%$ loss-to-follow up in the second year of the study, the actual sample sizes would be 3, 305 at time 1 and 2, 985 at time 2.

The 5-year cause-specific survival for women in Queensland diagnosed with invasive breast cancer when living within 2 hours road travelling time from a radiation facility is 0.897 , compared to 0.851 for women living further away (unpublished data, QCR). Applying these estimates to the anticipated sample size $(\mathrm{n}=2982 ; \mathrm{n}=2289<2 \mathrm{hrs} ; \mathrm{n}=$ $692 \geq 2 \mathrm{hrs}$ ) and using a two-sided log rank test, we would expect $80 \%$ power at a $5 \%$ significance level to detect an absolute survival difference of $4 \%$, or an approximate hazard ratio of 1.4. This equates to 356 breast cancer deaths expected among the study cohort within 5 years. Power calculations for the variation between and within area units (using Optimum Design software) are based solely on the approximate number of clusters (i.e. SLA) and records per cluster. We expect the sample at time 2 to cover 418 area units (SLAs), with between 1 and 69 (mean 
7.4 , median $=5$ ) respondents in each unit. Assuming 400 clusters with an average of 7 records per cluster and a baseline proportion of $50 \%$ gives $85 \%$ power at $0.05 \%$ significance to detect a difference in proportions between two groups of $6 \%$ at time 2 .

\section{Statistical analysis}

Statistical analyses will be conducted using a combination of standard empirical procedures and multilevel modelling (MLwiN 2.23). Time to diagnosis and treatment will be analysed using standard methods such as geometric mean (to account for anticipated skewed distribution of time to diagnosis and treatment) or the median

Multilevel modelling (Cox proportional hazards) includes individual-level factors (level 1) and the indicators of geographic remoteness and area socioeconomic disadvantage (level 2). This approach extends traditional (single-level) proportional hazards modelling by incorporating a random intercept that reflects the average survival outcome (time or probability) for each area. Corresponding models will be used for count (based on the Poisson or Negative binomial distribution) and categorical (based on the binomial distribution) data.

The multi-level modelling strategy consists of three stages. Firstly, building on the null (intercept only) model, this includes individual-level factors (such as patient characteristics, disease stage, co-morbidity, and access to health care and treatment services) as fixed effects. This will tell us how much of the area-variation in the breast cancer outcomes is due to these compositional factors; and also assess the contribution of each individual-level factor, including age to these outcomes. The second model extends Model 1 by including the area-level variables such as geographic remoteness and area socioeconomic disadvantage as fixed effects. This will quantify how much of the area-variation in the diagnostic pathway, treatment choices, unmet needs, and psychological adjustment and recurrence and survival is due to the area-level factors, independently of the individual-level factors. In the third model we specify cross-level interactions between the individual-level factors and geographic remoteness and area disadvantage. This analysis will tell us if the relationship between breast cancer outcomes and each of the individual-level factors differs as a function of geographic remoteness or area disadvantage.

\section{Discussion}

Breast cancer is the most common cancer in women in Australia. As the population increases and ages, the number of women diagnosed with breast cancer will increase, increasing the already significant burden on health care services. Inequalities in clinical and psychosocial outcomes, including poorer survival continue for women from rural and regional areas and for women from areas of disadvantage. The study will use an innovative approach to investigate reasons for these inequalities. Applying multi-level modelling techniques to examine area-level factors simultaneously with detailed individual-level factors will enable us to build a more complete picture of what are the important contributors to these known inequalities and how these factors relate to each other.

This study will enable us to determine whether geographical areas themselves have an impact on outcomes from breast cancer independently of the characteristics of the women who live in these areas. It will provide health care providers and policy makers with targeted information to improve the future management of women with breast cancer, and inform the development of strategies to improve psychosocial care for women with breast cancer.

\section{Acknowledgements}

This study is funded by Cancer Australia (ID 1006339). Associate Professor Peter Baade is supported by a National Health and Medical Research Council (NHMRC) Career Development Award (ID 1005334). Professor Suzanne Chambers is supported by a NHMRC Career Development Award (ID 496003). Associate Professor Gavin Turrell is supported by a NHMRC Senior Research Fellowship (ID 390109). Cancer Council Queensland provided additional funding for the GIS software maintenance and the ongoing follow-up of women in this study. Project staff are based at the Cancer Council Queensland. The assistance of Carla Shield, Rachel Austin and Carmen Connell in the submission of the original grant application is appreciated.

\section{Author details}

${ }^{1}$ Viertel Centre for Research in Cancer Control, Cancer Council Queensland, PO Box 201, Spring Hill, QLD, 4004, Australia. ${ }^{2}$ Griffith Health Institute, Gold Coast Campus, Griffith University, QLD, 4222, Australia. ${ }^{3}$ School of Public Health, Queensland University of Technology, Herston Road, Kelvin Grove, 4059, QLD, Australia. ${ }^{4}$ University of Queensland Centre for Clinical Research, Brisbane, QLD, Australia. ${ }^{5}$ Mater Breast Care Unit, Mater Hospital, Raymond Terrace, South Brisbane, QLD, 4001, Australia.

\section{Authors' contributions}

$\mathrm{PHY}$ led the writing for this manuscript and wrote the introduction, measures, and discussion. PDB wrote sections relating to the multilevel modelling and sample size components. All authors contributed to the design and data collection protocols, and wrote sections of the grant application that was used in the paper. All authors read and approved the manuscript.

\section{Competing interests}

The authors declare that they have no competing interests

Received: 26 August 2011 Accepted: 28 September 2011 Published: 28 September 2011

\section{References}

1. GLOBOCAN: Cancer Incidence and Mortality Worldwide. IARC CancerBase No. 10 [Internet]. International Agency for Research on Cancer Lyon, France; 2008.

2. Australian Institute of Health and Welfare \& Australasian Association of Cancer Registries: Cancer in Australia an overview 2010. Cancer Series no 60 Cat no CAN 56 Canberra: AlHW.

3. Begg S, Vos T, Barker B, Stevenson C, Stanley L, Lopez A: The burden of disease and injury in Australia 2003. PHE 82. AlHW, Canberra; 2007.

4. Zabora J, BrintzenhofeSzoc K, Curbow B, Hooker C, Piantadosi S: The prevalence of psychological distress by cancer site. Psychooncology 2001, 10(1):19-28. 
5. Girgis A, Boyes A, Sanson-Fisher RW, Burrows S: Perceived needs of women diagnosed with breast cancer: rural versus urban location. Aust N Z J Public Health 2000, 24(2):166-173.

6. Australian Institute of Health and Welfare \& National Breast and Ovarian Cancer Centre: Breast cancer in Australia: an overview, 2009. Cancer series no 50 Cat no CAN 46: AlHW Canberra; 2009.

7. Hall SA, Kaufman JS, Millikan RC, Ricketts TC, Herman D, Savitz DA Urbanization and Breast Cancer Incidence in North Carolina, 1995-1999. Annals of Epidemiology 2005, 15(10):796-803.

8. Gregorio Dl, Kulldorff M, Barry L, Samociuk H: Geographic differences in invasive and in situ breast cancer incidence according to precise geographic coordinates, Connecticut, 1991-95. Int J Cancer 2002, 100(2):194-198.

9. Youlden DR, Cramb SM, Baade PD: Current status of breast cancer in Queensland: 1982-2006. Viertel Centre for Research in Cancer Control, Cancer Council Queensland; Brisbane 2009.

10. Australian Institute of Health and Welfare \& National Breast Cancer Centre: Breast cancer survival by size and nodal status in Australia. Cancer Series no 39 Cat no CAN 34 AlHW, Canberra; 2007.

11. Thompson B, Baade $\mathrm{P}$, Coory M, Carriere $\mathrm{P}$, Fritschi L: Patterns of surgical treatment for women diagnosed with early breast cancer in Queensland. Ann Surg Oncol 2008, 15(2):443-451.

12. Mitchell KJ, Fritschi L, Reid A, McEvoy SP, Ingram DM, Jamrozik K, Clayforth C, Byrne MJ: Rural-urban differences in the presentation, management and survival of breast cancer in Western Australia. Breast 2006, 15(6):769-776.

13. Davis C, Williams P, Redman S, White K, King E: Assessing the practical and psychosocial needs of rural women with early breast cancer in Australia. Soc Work Health Care 2003, 36(3):25-36.

14. Burris $J$, Andrykowski M: Disparities in mental health between rural and nonrural cancer survivors: a preliminary study. Psychooncology 2009

15. Anders CK, Hsu DS, Broadwater G, Acharya CR, Foekens JA, Zhang Y, Wang Y, Marcom PK, Marks JR, Febbo PG, et al: Young age at diagnosis correlates with worse prognosis and defines a subset of breast cancers with shared patterns of gene expression. J Clin Oncol 2008, 26(20):3324-3330.

16. Axelrod D, Smith J, Kornreich D, Grinstead E, Singh B, Cangiarella J, Guth AA: Breast cancer in young women. J Am Coll Surg 2008, 206(3):1193-1203.

17. Bharat A, Aft RL, Gao F, Margenthaler JA: Patient and tumor characteristics associated with increased mortality in young women $(<$ or $=40$ years $)$ with breast cancer. J Surg Oncol 2009, 100(3):248-251.

18. Thewes B, Butow P, Girgis A, Pendlebury S: The psychosocial needs of breast cancer survivors; a qualitative study of the shared and unique needs of younger versus older survivors. Psychooncology 2004, 13(3):177-189.

19. Andersen BL, Carpenter KM, Yang HC, Shapiro CL: Sexual well-being among partnered women with breast cancer recurrence. J Clin Oncol 2007, 25(21):3151-3157.

20. Avis NE, Crawford S, Manuel J: Psychosocial problems among younger women with breast cancer. Psychooncology 2004, 13(5):295-308.

21. Fehlauer F, Tribius S, Mehnert A, Rades D: Health-related quality of life in long term breast cancer survivors treated with breast conserving therapy: impact of age at therapy. Breast Cancer Res Treat 2005, 92(3):217-222

22. Dunn J, Steginga SK: Young women's experience of breast cancer: defining young and identifying concerns. Psychooncology 2000, 9(2):137-146.

23. Cuzick J: Epidemiology of breast cancer-selected highlights. Breast Cancer Research \& Treatment 2003, 12(6):405-411.

24. McTiernan A: Behavioral risk factors in breast cancer: can risk be modified? Oncologist 2003, 8(4):326-334

25. Singletary KW, Gapstur SM: Alcohol and Breast Cancer: Review of Epidemiologic and Experimental Evidence and Potential Mechanisms. JAMA 2001, 286(17):2143-2151.

26. Monninkhof EM, Elias SG, Vlems FA, et al: Physical Activity and Breast Cancer: A Systematic Review. Epidemiology 2007, 18(1):137-157.

27. Dobson A, McLaughlin D, Vagenas D, Wong KY: Why are death rates higher in rural areas? Evidence from the Australian Longitudinal Study on Women's Health. Aust N Z J Public Health 2010, 34(6):624-628.

28. Hellmann SS, Thygesen LC, Tolstrup JS, Gronbaek M: Modifiable risk factors and survival in women diagnosed with primary breast cancer: results from a prospective cohort study. Eur J Cancer Prev 2010, 19(5):366-373.
29. Duffy SW, Smith RA, Gabe R, Tabar L, Yen AM, Chen TH: Screening for breast cancer. Surg Oncol Clin N Am 2005, 14(4):671-697.

30. Elmore JG, Armstrong K, Lehman CD, Fletcher SW: Screening for breast cancer. JAMA 2005, 293(10):1245-1256.

31. McDowell ME, Occhipinti S, Ferguson M, Chambers SK: Prospective predictors of psychosocial support service use after cancer. Psychooncology 2011, 20(7):788-791.

32. Australian Institute of Health and Welfare: BreastScreen Australia monitoring report 2005-2006. Cancer Series no. 48. Cat. no. CAN 44. AlHW: Canberra; 2009.

33. Mapping Rural and Regional Oncology Services in Australia. Clinical Oncological Society of Australia 2006

34. Halm EA, Lee C, Chassin MR: Is volume related to outcome in health care? A systematic review and methodologic critique of the literature. Ann Intern Med 2002, 137(6):511-520.

35. Martin-McDonald K, Rogers-Clark C, Hegney D, McCarthy A, Pearce S: Experiences of regional and rural people with cancer being treated with radiotherapy in a metropolitan centre. Int J Nurs Pract 2003, 9(3):176-182.

36. Condon JR, Armstrong BK, Barnes A, Cunningham J: Cancer in Indigenous Australians: a review. Cancer Causes Control 2003, 14(2):109-121.

37. AlHW: Rural, regional and remote Australia: a study on mortality. Australian Institute of Health and Welfare, Canberra; 2007.

38. Reynolds P, Hurley SE, Quach AT, Rosen H, Von Behren J, Hertz A, Smith D: Regional variations in breast cancer incidence among California women, 1988-1997. Cancer Causes Control 2005, 16(2):139-150.

39. Robert SA, Strombom I, Trentham-Dietz A, Hampton JM, McElroy JA, Newcomb PA, Remington PL: Socioeconomic risk factors for breast cancer: distinguishing individual- and community-level effects. Epidemiology 2004, 15(4):442-450.

40. Shack L, Jordan C, Thomson CS, Mak V, Moller H: Variation in incidence of breast, lung and cervical cancer and malignant melanoma of skin by socioeconomic group in England. BMC Cancer 2008, 8:271.

41. Bastiaannet E, de Craen AJ, Kuppen PJ, Aarts MJ, van der Geest LG, van de Velde CJ, Westendorp RG, Liefers GJ: Socioeconomic differences in survival among breast cancer patients in the Netherlands not explained by tumor size. Breast Cancer Res Treat 2010.

42. Ooi SL, Martinez ME, Li Cl: Disparities in breast cancer characteristics and outcomes by race/ethnicity. Breast Cancer Res Treat 2010.

43. Sprague BL, Trentham-Dietz A, Gangnon RE, Ramchandani R, Hampton JM, Robert SA, Remington PL, Newcomb PA: Socioeconomic status and survival after an invasive breast cancer diagnosis. Cancer 2010.

44. Albain KS, Green SR, Lichter AS, Hutchins LF, Wood WC, Henderson IC, Ingle JN, O'Sullivan J, Osborne CK, Martino S: Influence of patient characteristics, socioeconomic factors, geography, and systemic risk on the use of breast-sparing treatment in women enrolled in adjuvant breast cancer studies: an analysis of two intergroup trials. J Clin Oncol 1996, 14(11):3009-3017.

45. Gilligan MA, Kneusel RT, Hoffmann RG, Greer AL, Nattinger AB: Persistent differences in sociodemographic determinants of breast conserving treatment despite overall increased adoption. Med Care 2002, 40(3):181-189

46. Wyatt G, Beckrow KC, Gardiner J, Pathak D: Predictors of postsurgical subacute emotional and physical well-being among women with breast cancer. Cancer Nurs 2008, 31(2):E28-39.

47. Baade PD, Fritschi L, Aitken JF: Geographical differentials in cancer incidence and survival in Queensland: 1996 to 2002. Brisbane: Viertel Centre for research in Cancer Control Queensland Cancer Fund; 2005.

48. AlHW (Australian Institute of Health and Welfare) \& AACR (Australasian Association of Cancer Registries): Cancer survival in Australia 1992-1997: geographic categories and socioeconomic status. AlHW cat no CAN 17 Canberra: Australian Institute of Health and Welfare (Cancer series no 22) and Australiasian Association of Caner Registries 2003.

49. Subramanian SV, Duncan C: Multilevel perspectives on modeling census data. Environment and Planning A 2001, 33:399-417.

50. Regional Population Growth, Australia 2008-09. [http://www.abs.gov.au/ CDATAOnline]

51. Cancer in Queensland: Incidence and Mortality, 1982 to 2007. [http:// www.cancergld.org.au/icms_docs/60012_Cancer_in_QLD__incidence_and_mortality.pdf].

52. Steginga SK, Campbell A, Ferguson M, Beeden A, Walls M, Cairns W Dunn J: Socio-demographic, psychosocial and attitudinal predictors of 
help seeking after cancer diagnosis. Psychooncology 2008,

17(10):997-1005.

53. Bonevski B, Sanson-Fisher R, Girgis A, Burton L, Cook P, Boyes A: Evaluation of an instrument to assess the needs of patients with cancer. Supportive Care Review Group. Cancer 2000, 88(1):217-225.

54. Street RL Jr, Voigt B: Patient participation in deciding breast cancer treatment and subsequent quality of life. Med Decis Making 1997 17(3):298-306.

55. Jansen SJ, Otten W, Stiggelbout AM: Factors affecting patients' perceptions of choice regarding adjuvant chemotherapy for breast cancer. Breast Cancer Res Treat 2006, 99(1):35-45.

56. Jacobsen PB, Donovan KA, Trask PC, Fleishman SB, Zabora J, Baker F, Holland JC: Screening for psychologic distress in ambulatory cancer patients. Cancer 2005, 103(7):1494-1502.

57. Turner J, Hayes S, Reul-Hirche H: Improving the physical status and quality of life of women treated for breast cancer: a pilot study of a structured exercise intervention. J Surg Oncol 2004, 86(3):141-146.

58. Round T, Hayes SC, Newman B: How do recovery advice and behavioural characteristics influence upper-body function and quality of life among women 6 months after breast cancer diagnosis? Support Care Cancer 2006, 14(1):22-29.

59. AlHW: Rural, regional and remote health: A guide to remoteness classifications. Australian Institute of Health and Welfare AlHW Cat. No. PHE 53; 2004.

60. Australian Bureau of Statistics: Information Paper: An introduction to Socio-Economic Indexes for Areas (SEIFA). Cat. No. 2039.0. 2008.

\section{Pre-publication history}

The pre-publication history for this paper can be accessed here: http://www.biomedcentral.com/1471-2407/11/415/prepub

doi:10.1186/1471-2407-11-415

Cite this article as: Youl et al: A multilevel investigation of inequalities in clinical and psychosocial outcomes for women after breast cancer. BMC Cancer 2011 11:415.

\section{Submit your next manuscript to BioMed Central and take full advantage of:}

- Convenient online submission

- Thorough peer review

- No space constraints or color figure charges

- Immediate publication on acceptance

- Inclusion in PubMed, CAS, Scopus and Google Scholar

- Research which is freely available for redistribution

Submit your manuscript at www.biomedcentral.com/submit 